Research Article

\title{
Failure Behaviour of Sandstone with a Preexisting Joint under Stepped Excavation
}

\author{
Yinzhu Liu, ${ }^{1}$ Ping Cao, ${ }^{1}$ Liwen He, ${ }^{1}$ and Qibin Lin $\mathbb{D}^{1,2}$ \\ ${ }^{1}$ School of Resources and Safety Engineering, Central South University, Changsha 410083, China \\ ${ }^{2}$ Key Laboratory of Road Structure and Material of Ministry of Transport (Changsha), \\ Changsha University of Science \& Technology, Changsha 410114, China \\ Correspondence should be addressed to Qibin Lin; qblin@csu.edu.cn
}

Received 4 August 2020; Revised 18 August 2020; Accepted 21 August 2020; Published 31 August 2020

Academic Editor: Yixian Wang

Copyright (c) 2020 Yinzhu Liu et al. This is an open access article distributed under the Creative Commons Attribution License, which permits unrestricted use, distribution, and reproduction in any medium, provided the original work is properly cited.

\begin{abstract}
Much geotechnical construction needs to be carried out under the condition of stepped excavation. However, there is still a lack of research on crack coalescence and failure modes of jointed rock mass under stepped excavation conditions. In order to simulate the stepped excavation test of the real project, the polylactic acid (PLA) material is selected as the filler for the excavation area. The stepped excavation tests are performed on sandstone specimens containing a preexisting joint under different normal load conditions. The dynamic stepped excavation of simulating excavate rock engineering is realised. The constant normal loads during the excavation process are determined to be $80 \mathrm{kN}$ and $100 \mathrm{kN}$. The influence of the joint inclination on the failure characteristics of the excavation process is analysed. Four typical failure modes are summarised: (a) Mode I: crack coalescence of tensile failure; (b) Mode II: crack coalescence of mixed failure; (c) Mode III: without crack coalescence of mixed failure; (d) Mode IV: without crack coalescence of shear failure. Furthermore, the failure characteristics of the area above the excavation hole and the preexisting joint are analysed. The results show that there are three failure modes: (a) Type I: spalling failure; (b) Type II: shear slip failure; (c) Type III: shear slip and spalling mixed failure.
\end{abstract}

\section{Introduction}

There are a large number of discontinuous structural planes such as joint $[1,2]$, fault $[3,4]$, and bedding plane $[5,6]$ in the natural rock mass. Many engineering practices have shown that the existence of these discontinuities is one of the main causes of engineering problems and engineering accidents [7-9]. Researching and exploring the failure mechanisms of roadways and tunnels under complex geological conditions has crucial engineering significance for ensuring construction safety.

It is difficult to control the spatial location and geometric size of joints in natural rock materials. Most scholars used the method of water-jet cutting to make jointed rock (such as sandstone [10], granite [11, 12], and marble [13]) with a single joint [14], two joints [15], or three joints [16]. However, the use of natural rock materials can only make a jointed rock specimen with simple joint geometry distribution $[17,18]$. However, in natural rock masses, joints generally appear in groups $[19,20]$. Therefore, scholars choose to use rocklike materials [21] to make different spatial distributions and different numbers of joints [22, 23]. The effect of joints on the mechanical behaviour of the jointed rocklike specimen was studied. There are two main types of joints: open joint [24] and closed joint [25]. The above research results show that the joint has an essential impact on the failure properties of the specimen. Specifically, the joint will reduce the mechanical behaviour of the rock mass. Under uniaxial loading, there are three main crack coalescence modes, namely, tensile crack, shear crack, and mixed crack. The failure behaviour of jointed rock mass is mainly related to the geometric structure parameters of the joint, including joint inclination, joint spacing, and rock bridge angle.

The natural rock mass contains not only the joint defect but also hole defect [26]. On the microscale, there are many 
holelike defects in the rock [27]. On the macroscale, the excavation of rock engineering (such as tunnels, roadways, and subways) will form hole defects [28]. Li et al. [29] analysed the crack propagation process of marble samples with holes by digital image correlation (DIC) technology. $\mathrm{Wu}$ et al. [30] studied the influence of five different hole shapes on the mechanical properties of sandstone rock through a series of uniaxial loading tests. Gui et al. [31] adopted the Universal Distinct Element Code (UDEC) software to investigate the effect of hole size, hole number, and hole distribution on the mechanical behaviour of the specimen. Scholars have also carried out a lot of research on the influence of holes and joint combination effect on the failure behaviour. Fan et al. [32] used Particle Flow Code in 3D (PFC3D) software to analyse the distribution of the stress field around the hole in detail. Cao et al. [33] studied the effect of joint inclination and spacing on the strength and failure mode of a jointed specimen with a hole. Lin et al. $[34,35]$ introduced double holes into the jointed rock mass and established the jointed rock mass with the double holes model. The crack inclination mode between joints and holes was summarised.

Scholars have performed many kinds of research on joint and hole defects, enriching the understanding of jointed rock masses. However, most geotechnical engineering is carried out under the condition of stepped excavation. When excavating a roadway, due to the discontinuous structural planes of the upper rock mass, the failure behaviour of the rock mass becomes unstable during the excavation process. The crack initiation and propagation inside the rock mass are also the main reasons for the collapse of the roadway. Therefore, the crack coalescence modes of the jointed rock mass under the condition of stepped excavation are analysed in this study. The failure mode is further investigated. The findings will have important engineering significance for tunnel construction and support in rock engineering projects.

\section{Sample Preparation and Experimental Design}

2.1. Sample Preparation. To avoid the dispersion of the test results, the sandstone samples are collected from the same rock block. The water-jet cutting is used in producing sandstone samples with different joint inclinations and the same geometric parameter of the hole. The geometric distribution of the sample is shown in Figure 1(a). The sample size is $200 \mathrm{~mm}$ (height) $\times 150 \mathrm{~mm}$ (length) $\times 30 \mathrm{~mm}$ (width). The joint inclination $\alpha$ between the preexisting joint and the horizontal direction is selected as five angles, which are $0^{\circ}$, $30^{\circ}, 45^{\circ}, 60^{\circ}$, and $90^{\circ}$, as shown in Figure $1(\mathrm{~b})$. The width and length of the preexisting joint are $2.5 \mathrm{~mm}$ and $40 \mathrm{~mm}$, respectively. The circular hole radius is $25 \mathrm{~mm}$ and is located $55 \mathrm{~mm}$ directly below the preexisting joint. The distance between the hole and the end of the sample is $75 \mathrm{~mm}$. The polylactic acid (PLA) is selected as a filling material to fill the excavation area. The PLA material is granular in shape at room temperature and needs to be converted into liquid form by hot melt in advance, and then, it is used to fill the excavation area.

According to the method recommended by the International Society of Rock Mechanics [36], the cylinder samples of $100 \mathrm{~mm}$ (height) $\times 50 \mathrm{~mm}$ (diameter) and $25 \mathrm{~mm}$ (height) $\times 50 \mathrm{~mm}$ (diameter) are used for the uniaxial compression test and Brazilian split test, respectively. The basic mechanical parameters of sandstone and PLA material are obtained, as shown in Table 1. The uniaxial compressive and tensile strength of polylactic acid resin is slightly higher than that of sandstone samples. Due to its low melting point, the PLA material will melt after the applied temperature reaches $180^{\circ} \mathrm{C}$ [37]. Therefore, the material properties of the excavation area can be similar to that of the surrounding rock. And it will not cause the PLA material to soften due to temperature rise. It can ensure that the experimental samples can effectively undergo the stepped excavation test.

2.2. Experimental Design. The test is performed on the electrohydraulic servo testing machine. The loading method adopted is force-controlled loading, and the loading rate is 200 N/S. It can be seen from Table 1 that the uniaxial compressive strength of sandstone is $25.96 \mathrm{MPa}$. After many pretests, it was found that when the following two stress values were used, the requirements of the stepped excavation test could be met. That is, the lower value is $17.78 \mathrm{MPa}$ $(80 \mathrm{kN})$, which is $68.49 \%$ of the uniaxial compressive strength; the higher value is $22.22 \mathrm{MPa}(100 \mathrm{kN})$, which is $85.59 \%$ of the uniaxial compressive strength. After the normal load reached the set load and remained stable, the stepped excavation test is started. The excavation method is the hot melt method, and the specific operation is to use a special electric hot cutter to melt the excavation area in the test sample at equal distances, as shown in Figure 2. It is divided into three excavation steps, and each excavation is $10 \mathrm{~mm}$. After each excavation operation, wait for 1 minute for the specimen to reach the equilibrium of the stress state again, and then proceed to the next excavation operation. The samples are numbered in the form of S-A-B, where A represents the inclination of the preexisting joint and $B$ represents the set load, as shown in Table 2. For example, S-30-80 represents a sample with a preexisting joint inclination of $30^{\circ}$ and under the condition of normal load of $80 \mathrm{kN}$.

\section{Results Analysis}

3.1. Crack Evolution Process. Previous studies [38, 39] indicated that there are two types of cracks at the tip of the joint under uniaxial loading: wing crack and secondary crack, as displayed in Figure 3. The wing crack is usually a tensile crack, which first occurs in the specimen. Its propagation direction is generally parallel to the loading direction. During the wing crack propagation process, secondary crack is gradually generated and usually is shear crack. Because of its propagation and coalescence, it is easier to cause the overall damage of the specimen. 


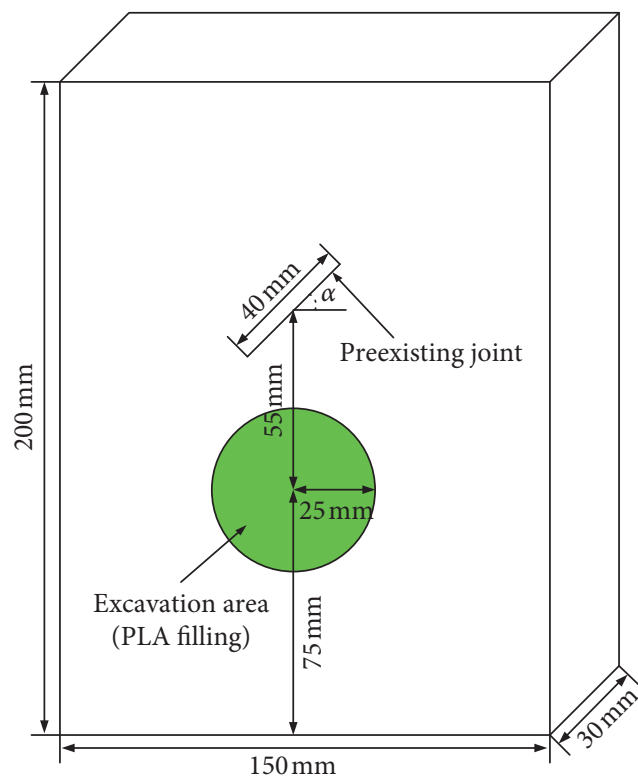

(a)

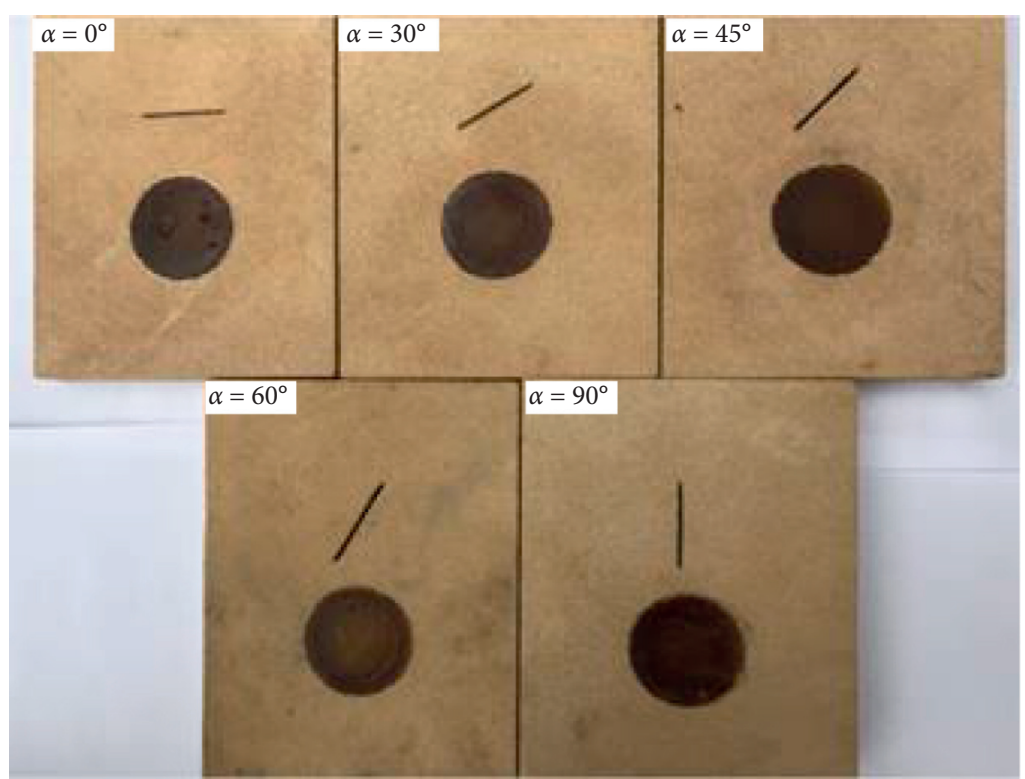

(b)

FIgURE 1: (a) Schematic diagram of the geometric parameters of preexisting joint and excavation area. (b) Experimental samples.

TABLe 1: Physical and mechanical properties of sandstone and PLA material.

\begin{tabular}{lcccc}
\hline Material & Density $\left(\mathrm{kg} / \mathrm{m}^{3}\right)$ & Uniaxial compressive strength $(\mathrm{MPa})$ & Tensile strength $(\mathrm{MPa})$ & Elastic modulus $(\mathrm{GPa})$ \\
\hline Sandstone & 2185 & 25.96 & 2.29 & 1.96 \\
PLA & 1235 & 27.87 & 8.65 & 1.52 \\
\hline
\end{tabular}

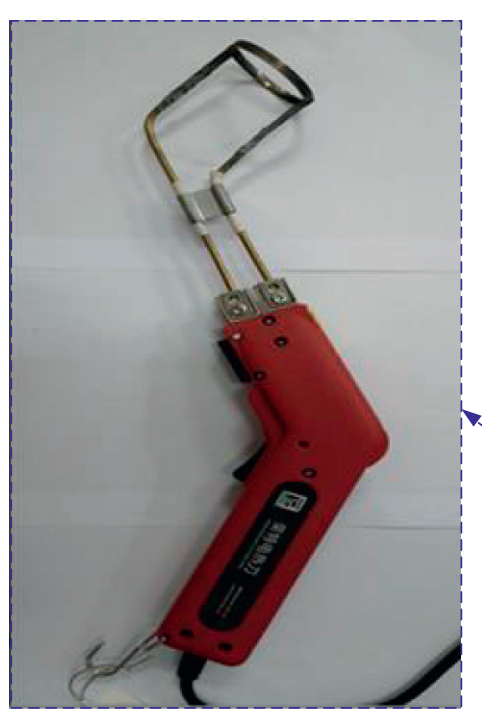

(a)

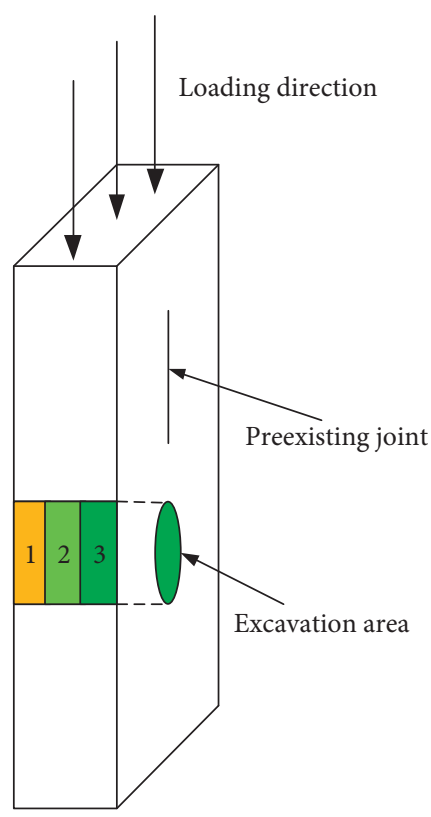

(b)

FIgURE 2: (a) Electric hot cutter. (b) Schematic diagram of the stepped excavation test.

Figure 4(a) shows the crack propagation process of S-080 during the stepped excavation. It can be found that S-0-80 has no visible crack propagation phenomenon in the three- step excavation test. Until the end of the test, there is no overall damage to the specimen. When the normal load is increased to $100 \mathrm{kN}$, after the first step of excavation and 
TABle 2: The tested samples under the stepped excavation test.

\begin{tabular}{lccc}
\hline Number & Sample ID & Joint inclination $\left(^{\circ}\right)$ & Normal load $(\mathrm{kN})$ \\
\hline 1 & S- $0-80$ & 0 & 80 \\
2 & S- -100 & 0 & 100 \\
3 & S- $30-80$ & 30 & 80 \\
4 & S- $30-100$ & 30 & 100 \\
5 & S- $45-80$ & 45 & 80 \\
6 & S- $45-100$ & 45 & 100 \\
7 & S-60-80 & 60 & 80 \\
8 & S-60-100 & 60 & 100 \\
9 & S- $90-80$ & 90 & 80 \\
10 & S- $90-100$ & 90 & 100 \\
\hline
\end{tabular}

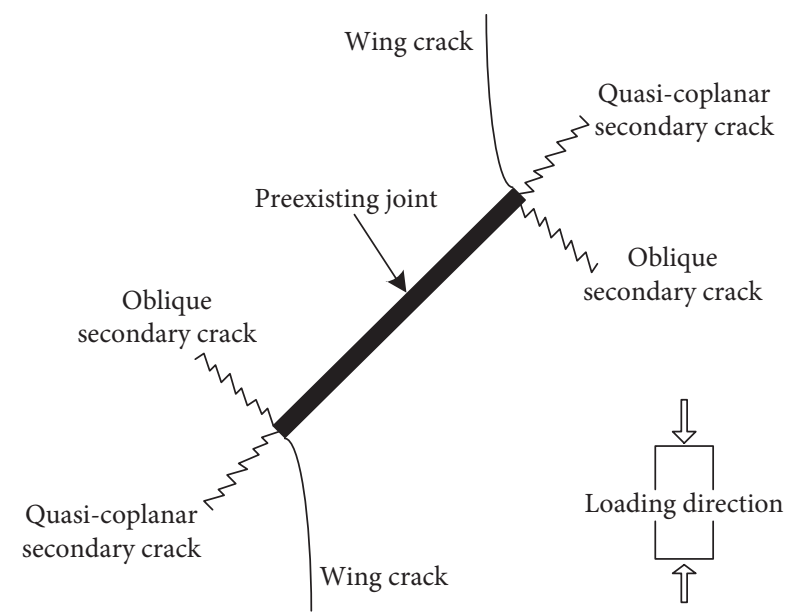

FIGURE 3: Crack types observed in the preexisting joint specimen under uniaxial loading $[38,39]$.

unloading is completed, two tensile cracks 1 and 2 can be seen at both ends of the preexisting joint, as shown in Figure 4(b). In the subsequent crack propagation process, it only extends to both sides of the hole. Until the second excavation is completed, the tensile cracks 1 and 2 coalesce on both sides of the hole. Subsequently, crack 4 that originated on the right side of the excavation area coalesces with crack 5. Crack 6 coalesces with the tensile crack 7 that occurs on the upper-left corner, and the specimen is finally destroyed.

As shown in Figure 5(a), the crack propagation process of S-30-80 is similar to that of S-0-80. During the excavation process, the specimen does not undergo overall damage. Figure 5(b) shows the crack evolution process of S-30-100. After the first step of excavation, no apparent cracks appear on the surface of the sample. After the completion of the second step of excavation, it is found that crack 1 appears on the upper-left corner, which is a tensile crack. The crack propagation direction is parallel to the loading direction and continues to expand downward. Crack 1 coalesces with crack 2 on the left side of the hole, and the surface of the sample is partially collapsed. When the third step of excavation is completed, a tensile crack 3 appears at the tip of the joint, which coalesces with the crack above the hole. At the same time, a tensile crack 4 appears at the right end of the joint and continues to expand until it coalesces to the right of the excavation area. Finally, the specimen loses its bearing capacity.

As shown in Figure 6(a), during the three-step excavation process, there is no visible crack initiation and propagation appears in S-45-80. As shown in Figure 6(b), after the first step of excavation of S-45-100, no apparent crack initiation appears on the surface of the specimen. After the second step of excavation and unloading operation is completed, the test specimen is severely damaged, and crack 1 appears on the right end of the specimen, coalescing with the excavation hole. A wing crack 2 appears at the right tip of the joint, which expands upward to the boundary of the specimen. At the same time, a wing crack 3 appears at the left tip of the joint, which expands downward until it coalesces with the crack above the hole. In the area on the left side of the specimen, a lot of damage occurs. The cracks appear on the left side of the hole and quickly propagate to the boundary of the specimen, resulting in the overall failure of the specimen.

As shown in Figure 7(a), when the joint inclination is $60^{\circ}$, the failure of the specimen is different from other joint inclinations. The first and the second excavations do not have a significant influence on the specimen, and no apparent crack initiation occurs on the surface of the specimen. However, after the completion of the third step of excavation, a large number of shear cracks appear on both sides of the excavated hole. Cracks 3 and 4 on both sides of the excavation hole expand rapidly, penetrating the lower-left and upper-right corners of the specimen, and form two macroscopic shear failure zones on the surface of the specimen. As shown in Figure 7(b), when the normal load is increased to $100 \mathrm{kN}$, when the second step of excavation is completed, a tensile crack 1 is formed on the right side of the hole, which expands parallel to the loading direction. Subsequently, a shear crack 2 appears in the lower-left corner of the excavated hole and propagates to the bottom of the specimen. When the third step of excavation is completed, cracks 1 and 2 continue to expand, eventually leading to damage to the specimen.

As shown in Figure 8(a), S-90-80 does not undergo overall damage during the excavation process. As shown in Figure 8(b), after S-90-100 completes the first two steps of excavation, there is no obvious crack initiation on the surface of the test specimen. Until the third step of excavation is completed, cracks 1 and 2 appear on the left side of the excavated hole and extend to the boundary of the specimen, resulting in the overall failure of the specimen.

3.2. Failure Characteristics. According to the final failure characteristics of the specimen and whether the hole is coalesced to the preexisting joint, the failure modes of the specimen are divided into the following four categories: (a) Mode I: crack coalescence of tensile failure; (b) Mode II: crack coalescence of mixed failure; (c) Mode III: without crack coalescence of mixed failure; (d) Mode IV: without crack coalescence of shear failure, as shown in Figure 9.

Mode I occurs in S-30-100, as shown in Figure 9(a). It can be noticed that tensile cracks appear in the upper-left 

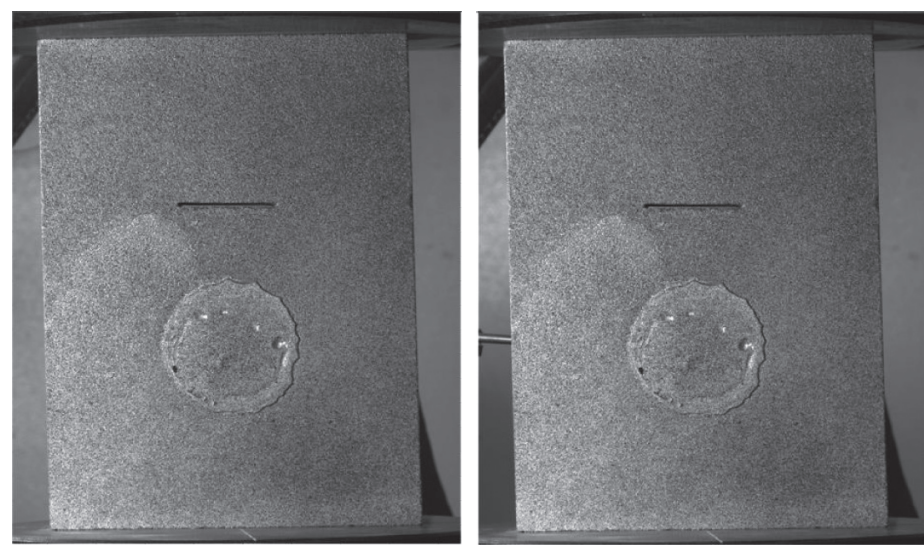

(a)
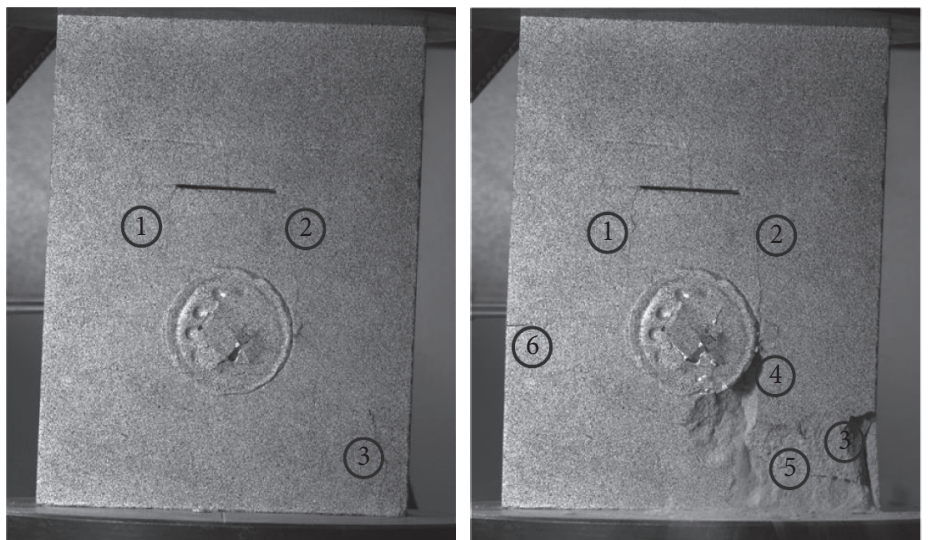

(b)
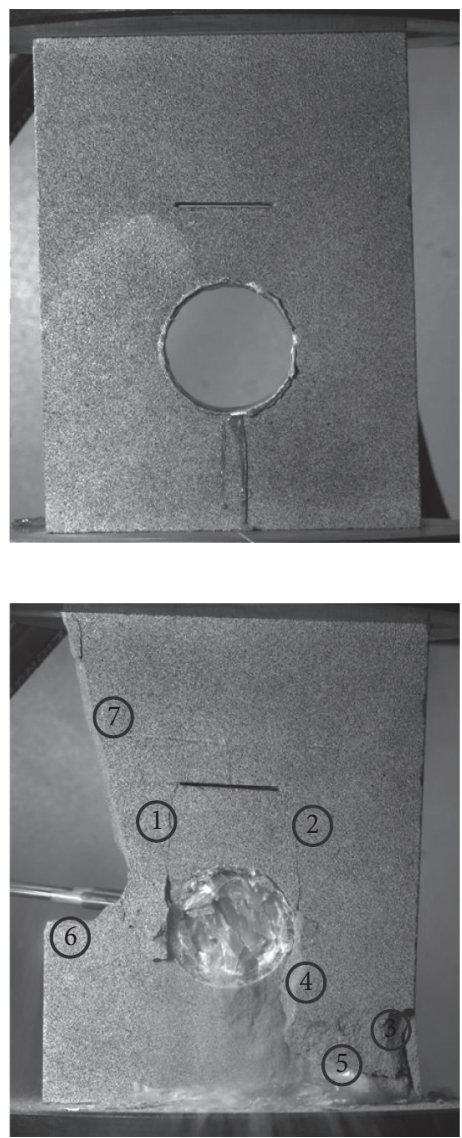

FIgURE 4: Crack evolution process of $\alpha=0^{\circ}$ : (a) S-0-80; (b) S-0-100.

corner of the sample and continue to propagate. Then, tensile cracks occur at the left and right tips of the joint, which coalesces with the hole. Finally, the sample undergoes tensile failure. Mode II mainly appears in S-0-100 and S-45100. As shown in Figure 9(b), the cracks that cause the joint to coalesce with the excavation area are all tensile cracks. The shear cracks that appear during the test all occur in the lower-left or right corner of the specimen, and there is a visible shear friction area. Figure 6(b) shows that the failure process of S-45-100 is very rapid. From the initiation of the crack to the overall failure of the specimen, the time is extremely short. The crack coalescence is that wing cracks are generated at both ends of the preexisting joint; one extends downward to coalesce with the excavation area, and the other extends upward to penetrate the specimen. Stress concentration occurred in the area around the excavation hole, which caused a shear crack in the lower-left corner of the specimen, resulting in tensile-shear mixed failure. However, S-0-100 has a longer failure process. The crack coalescence mode is that the tensile cracks initiate at both ends of the preexisting joint, which propagate downward to coalesce with the excavation hole. The shear crack appears in the lower-right corner of the specimen, and the tensile crack appears at the left end of the specimen. Finally, the tensile and shear mixed failure of the specimen occurs, as shown in Figure 4(b). Mode III occurs in S-60-100. The preexisting joint without crack coalescence of mixed failure with the holes can be noticed, as displayed in Figure 9(c). The shear crack initiates at the lower-left corner of the excavation hole and spreads to the lower-left corner of the specimen. The stress concentration around the excavated hole causes this failure mode. A large number of cracks appear around the excavation hole and expand to the edge of the specimen, resulting in the final failure of the specimen. The cracks initiate on both sides of the hole and finally divide the specimen into two parts. Mode IV appears in S-90-100. As shown in Figure 9(d), two shear cracks are generated at the left end of the specimen, which coalesces with the upper-left corner and the lower-left corner of the specimen and subsequently causes the overall damage of the specimen.

3.3. Failure Mode between the Hole and Joint. In actual engineering projects, the excavation of roadways or tunnels often encounters complicate geological conditions such as rock faults above the roads. Among them, the collapse of the roof is one of the most common safety accidents. Therefore, analysing the failure mode between the joint and the excavated area is of considerable significance to the actual engineering. On the contrary, although the preexisting joint does not coalesce with the excavation hole, they have a 

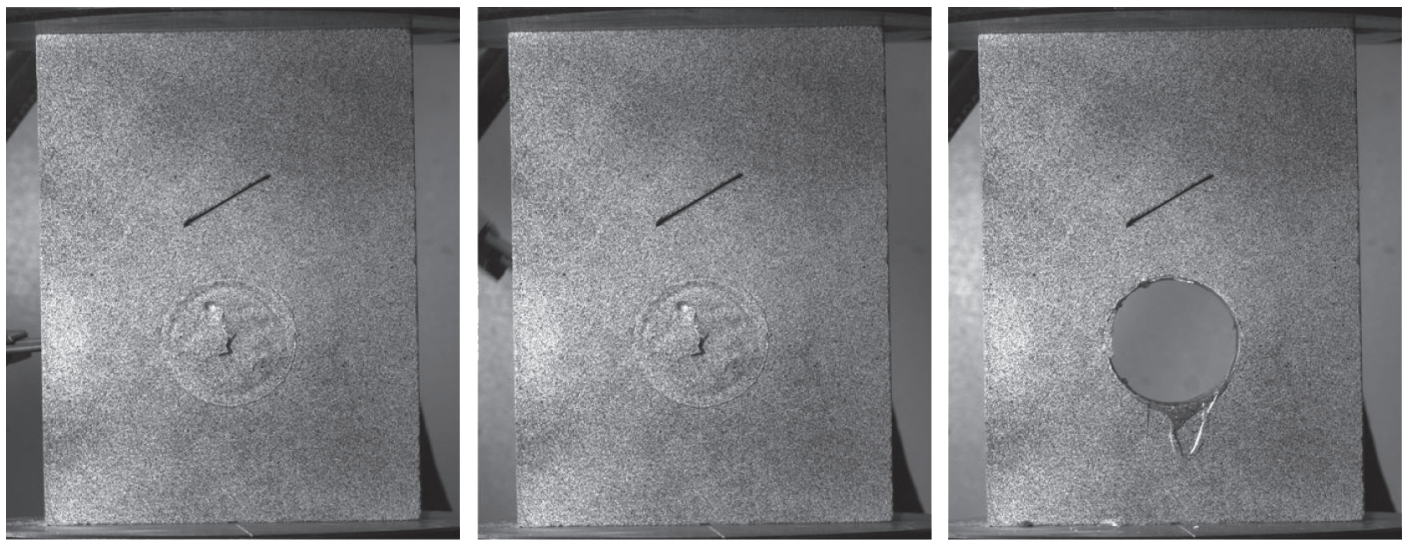

(a)
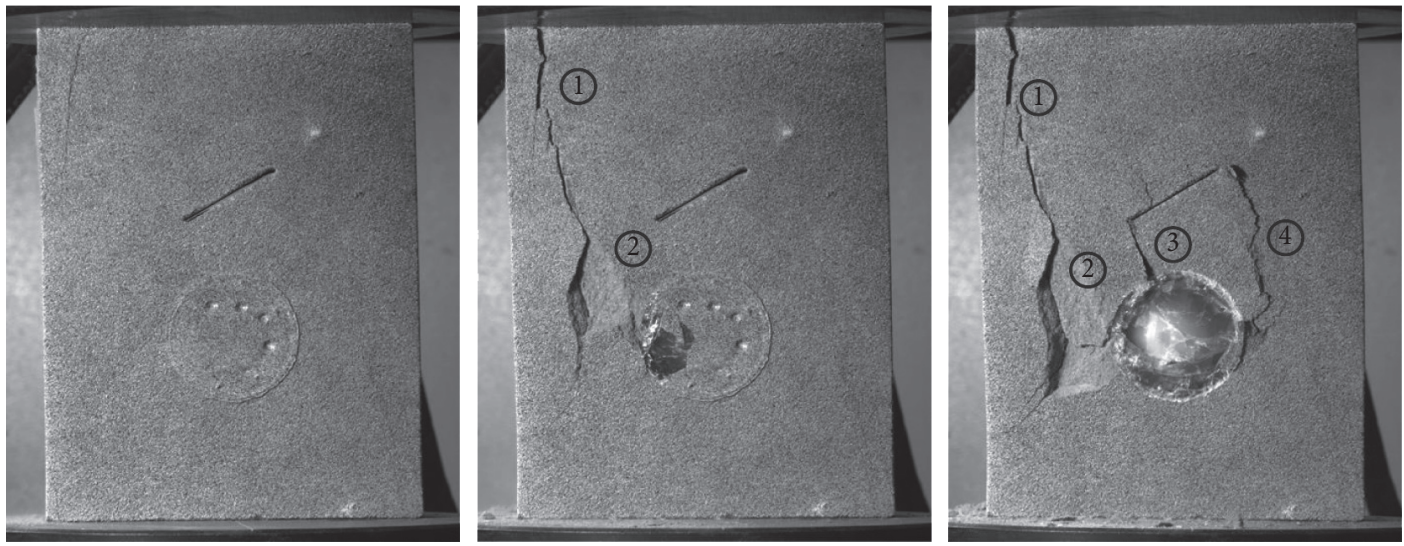

(b)

FIGURE 5: Crack evolution process of $\alpha=30^{\circ}$ : (a) S-30-80; (b) S-30-100.
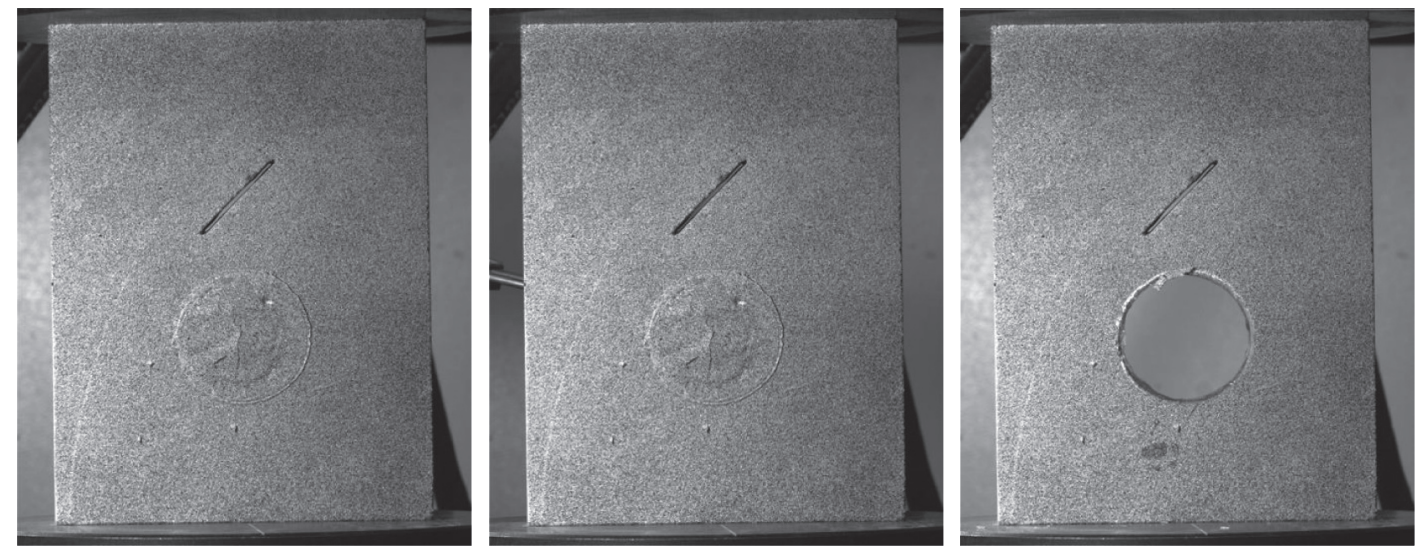

(a)

Figure 6: Continued. 

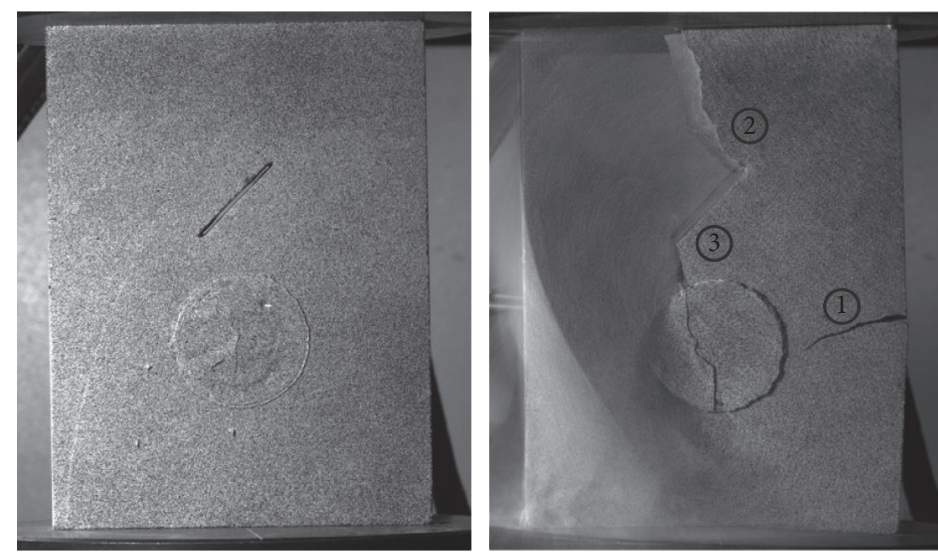

(b)

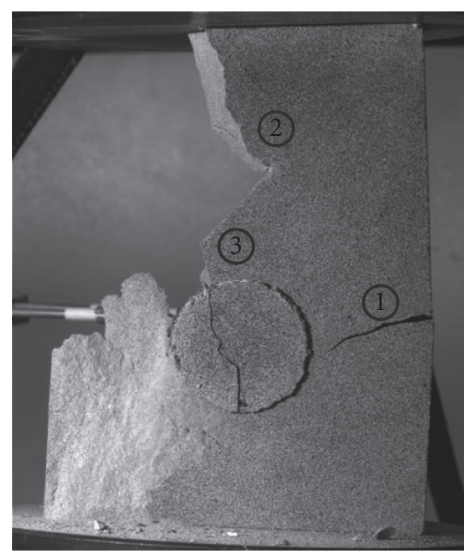

; (b) S-45-100.
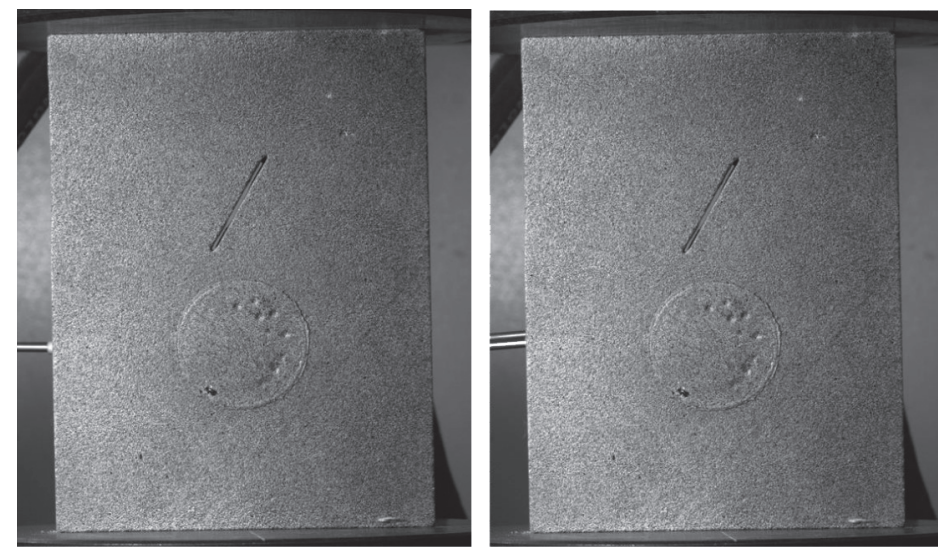

(a)
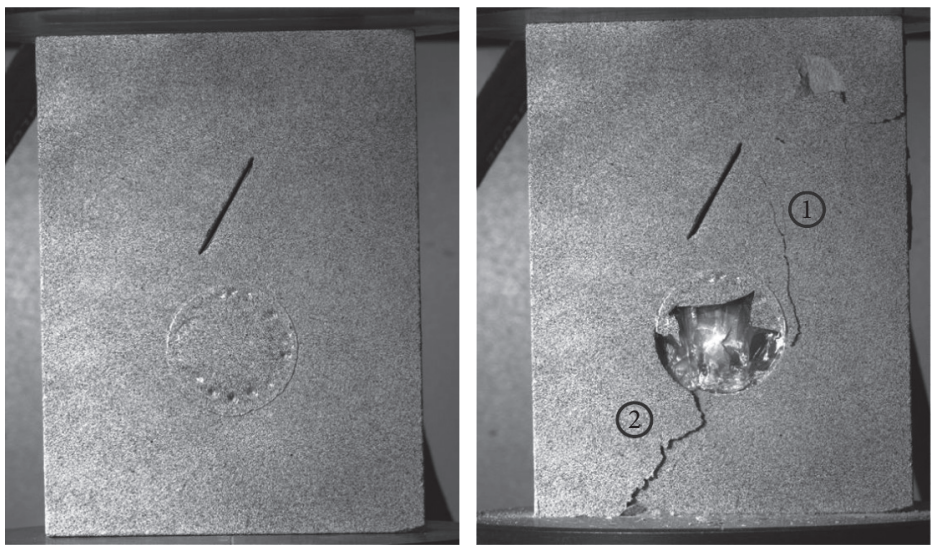

(b)
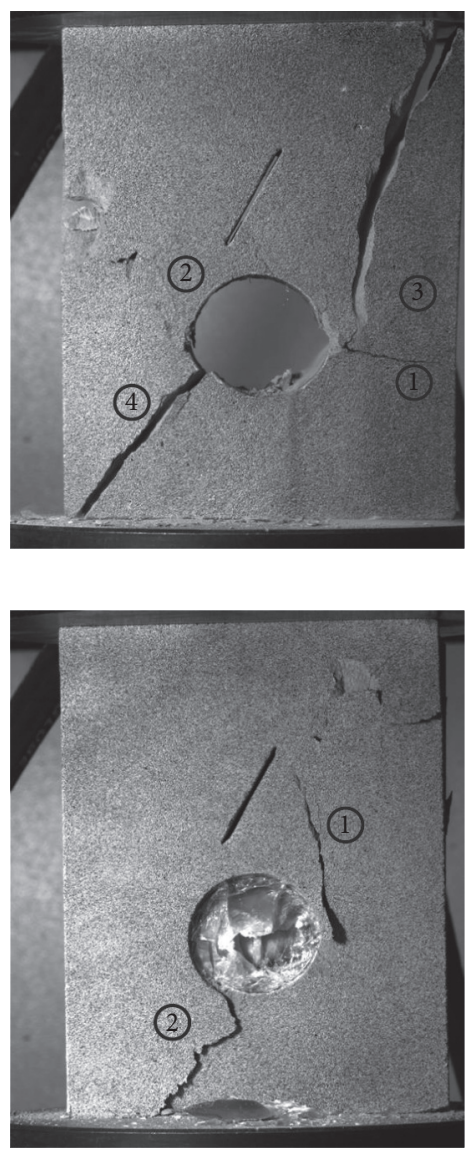

Figure 7: Crack evolution process of $\alpha=60^{\circ}$ : (a) S-60-80; (b) S-60-100.

significant influence on the stress field distribution, causing stress concentration and damage around the excavation area. Through analysing the crack coalescence around the excavation hole, three main failure modes are summarised: (a) Type I: spalling failure; (b) Type II: shear slip failure; (c) Type III: shear slip and spalling mixed failure.
Type I mainly appeared in S-0-100 and S-30-100. As shown in Figure 10(a), taking S-30-110 as an example, the area above the excavation has a typical spalling failure. During the failure process, a tensile crack appears in the tip of the joint and propagates downward parallel to the loading direction. The crack coalesces with the excavation hole. This 

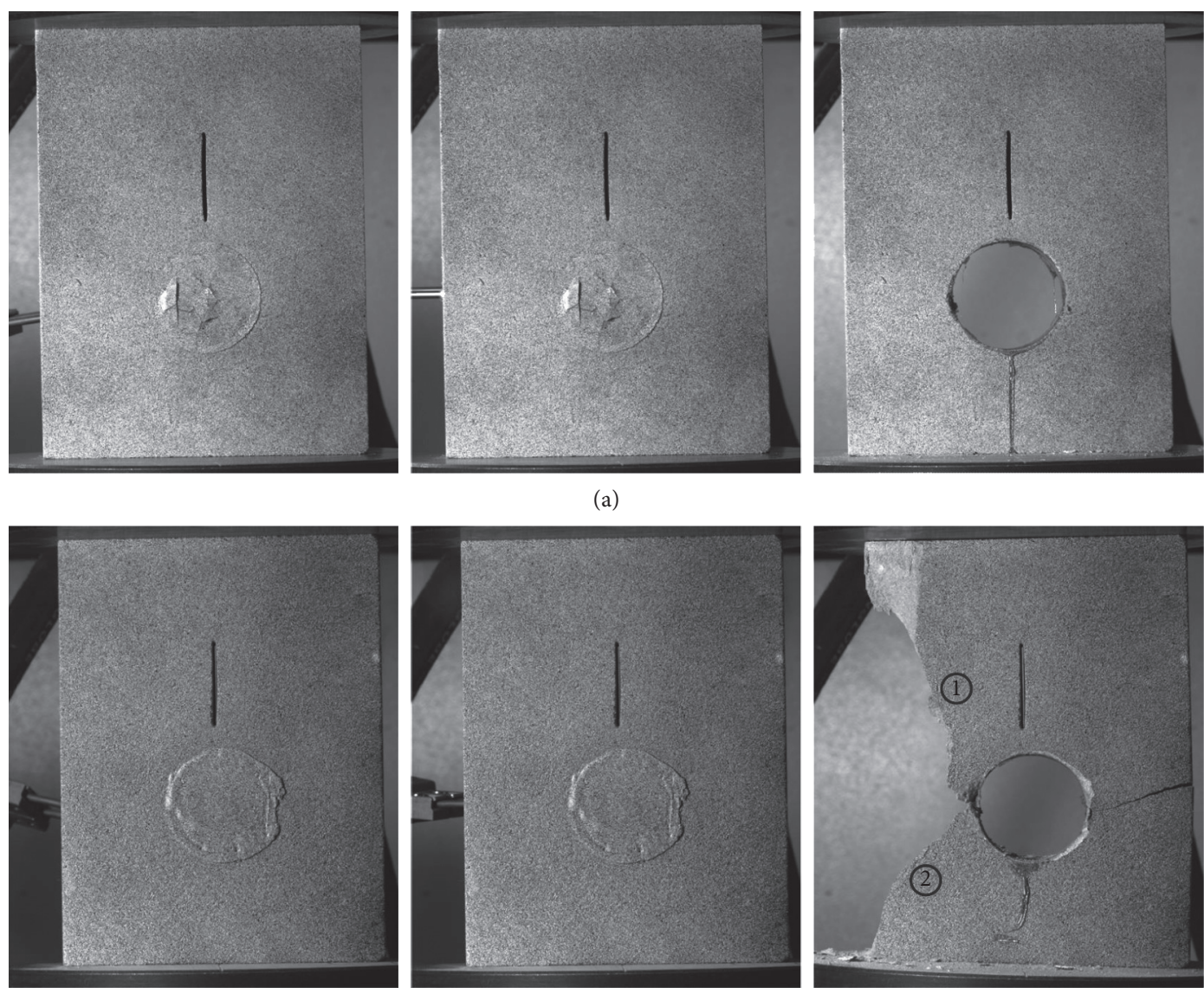

(b)

FIGURE 8: Crack evolution process of $\alpha=90^{\circ}$ : (a) S-90-80; (b) S-90-100.

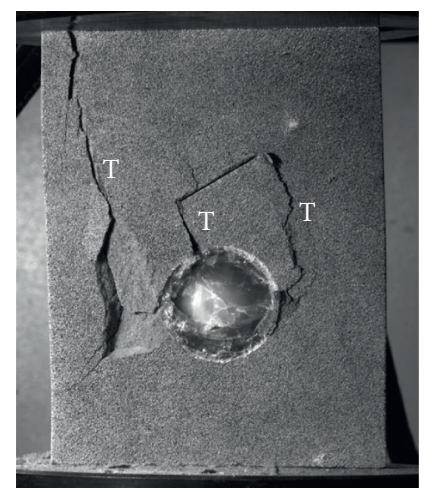

(a)

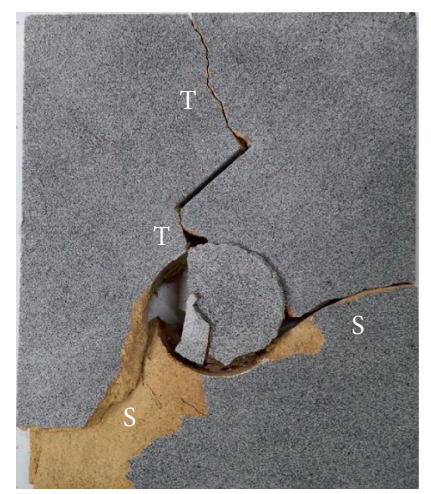

(b)

Figure 9: Continued. 


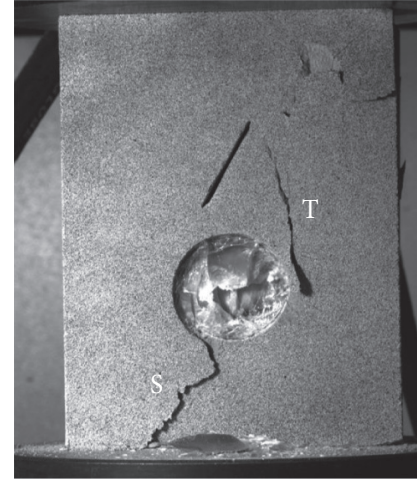

(c)

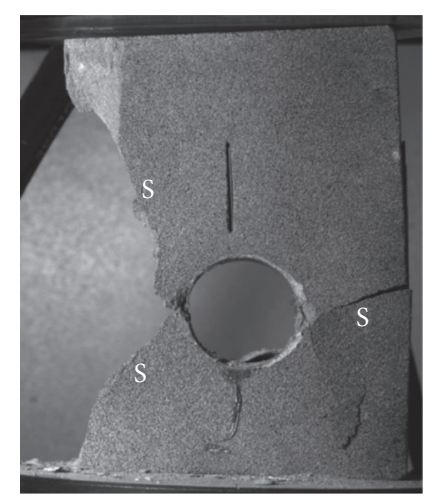

(d)

Figure 9: Typical failure mode observed in the present experiment (T: tensile crack; S: shear crack). (a) Mode I, (b) Mode II, (c) Mode III, and (d) Mode IV.
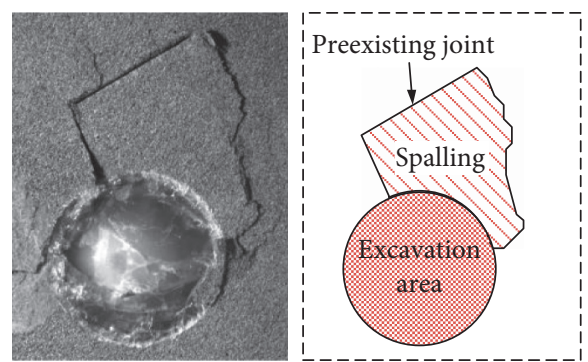

(a)
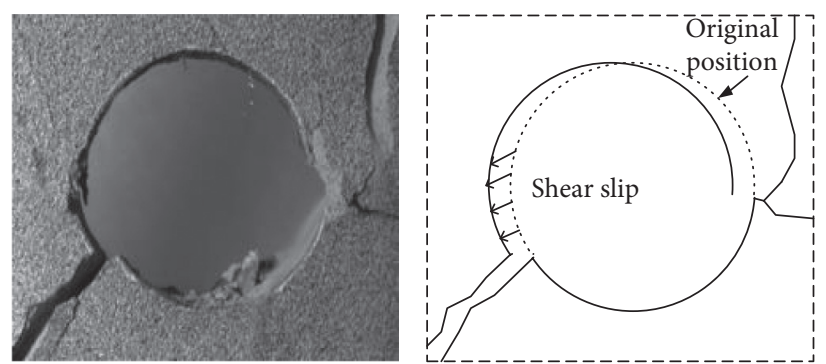

(b)
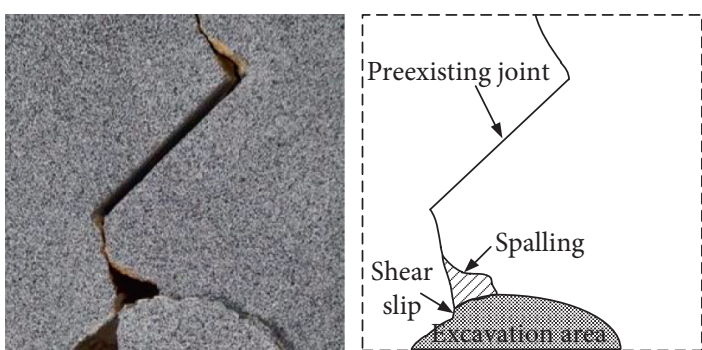

(c)

Figure 10: Failure modes between the hole and joint. (a) Type I, (b) Type II, and (c) Type III.

type of failure mode generally appears in specimens with small joint inclinations, such as $0^{\circ}$ and $30^{\circ}$. Type II mainly appeared in S-60-80. As shown in Figure 10(b), two shear cracks on both sides of the hole caused the shear failure surface to move up and down. A relatively apparent displacement also appears on the failure surface on the right side of the excavated hole. Compared with the original excavation hole, it can be seen that there is a shear displacement on the right side of the excavation area. This is because the specimen produces two shear cracks during the failure process. Under the action of normal stress, the failure surface of the specimen receives a component force. The upper and lower parts of the fracture surface slide relatively. The failure mode requires the specimen to produce shear cracks that coalesce with the end of the specimen and the excavation area. It can provide large shear stress on the crack surface, which causes a large sliding dislocation of the specimen. Eventually, the excavation area undergoes the shear slip failure and damages downward. This type of failure mode mainly occurs in the specimens with large joint inclination. When the shear slip failure mode in the excavation zone appears, the overall failure of the specimen is mainly shear failure. Type III mainly appears in the failure process of S-45-100. As shown in Figure 10(c), there is a shear slip failure and part of the spalling failure in the area above the excavation hole. The overall failure mode is a mixed failure of shear slip and spalling. The failure surfaces have both shear and tensile cracks. It can be observed that the top of the excavation hole has a vertical displacement due to the shear slip in the lower-left corner. 
Another crack at the left tip of the joint coalesces with the excavation hole. The shear slip phenomenon also appears in the excavation hole. This indicates that this failure mode is a mixed failure.

\section{Conclusion}

In this study, a series of stepped excavation tests of jointed rock mass has been carried out. The PLA material was selected to fill the excavation area. The results show that the joint inclination plays a vital role in the crack coalescence and failure mode of the rock mass during the stepped excavation. The following conclusions can be drawn:

(1) The crack coalescence between the preexisting joint and the excavation area mostly occurs in tensile cracks. With the increase in the joint inclination, the cracks that dominate the failure of the specimen change from tensile cracks to shear cracks. The cracks between the excavation area and the joint gradually decrease. When the joint inclination increases to $60^{\circ}$, the crack does not coalesce with the excavation area.

(2) Four categories of failure modes are identified: Mode I (crack coalescence of tensile failure); Mode II (crack coalescence of mixed failure); Mode III (without crack coalescence of mixed failure); Mode IV (without crack coalescence of shear failure).

(3) Three types of failure modes between the hole and joint are found: Type I (spalling failure); Type II (shear slip failure); Type III (shear slip and spalling mixed failure). When the joint inclination is small $\left(\alpha=0^{\circ}\right.$ and $30^{\circ}$ ), the spalling failure is easier to occur in the excavation area. With the increase of joint inclination $\left(\alpha=45^{\circ}\right)$, the excavation area is prone to undergo shear slip failure. When the joint inclination reaches $60^{\circ}$, the shear slip and spalling mixed failure is likely to occur in this area. With the increase of the joint inclination, the failure mode of the excavation area gradually changes from the spalling failure to the shear slip failure.

\section{Data Availability}

Data are available on request.

\section{Conflicts of Interest}

The authors declare that they have no conflicts of interest.

\section{Acknowledgments}

This research was supported by the National Natural Science Foundation of China (11772358), the Water Conservancy Science and Technology Major Project of Hunan Province, China (XSKJ2019081-10), and the Open Fund of Key Laboratory of Road Structure and Material of Ministry of Transport (Changsha University of Science \& Technology) (kfj170305).

\section{References}

[1] S. Xie, H. Lin, Y. Chen, R. Yong, W. Xiong, and S. Du, “A damage constitutive model for shear behavior of joints based on determination of the yield point," International Journal of Rock Mechanics and Mining Sciences, vol. 128, p. 104269, 2020.

[2] Y. Zhao, L. Zhang, W. Wang et al., "Experimental study on shear behavior and a revised shear strength model for infilled rock joints," International Journal of Geomechanics, vol. 20, no. 9, Article ID 04020141, 2020.

[3] S. Xie, H. Lin, Y. Wang et al., "A statistical damage constitutive model considering whole joint shear deformation," International Journal of Damage Mechanics, vol. 29, no. 6, pp. 988-1008, 2020.

[4] Y. Zhao, L. Zhang, W. Wang, J. Tang, H. Lin, and W. Wan, "Transient pulse test and morphological analysis of single rock fractures," International Journal of Rock Mechanics and Mining Sciences, vol. 91, pp. 139-154, 2017.

[5] J. Shang, "Rupture of veined granite in polyaxial compression: insights from three-dimensional Discrete Element Method modeling," Journal of Geophysical Research: Solid Earth, vol. 125 , no. $2,2020$.

[6] S. Xie, H. Lin, Y. Wang et al., "Nonlinear shear constitutive model for peak shear-type joints based on improved Harris damage function," Archives of Civil and Mechanical Engineering, vol. 20, no. 3, pp. 1-14, 2020.

[7] Q. Lin, P. Cao, H. Wang et al., "An experimental study on cracking behavior of precracked sandstone specimens under seepage pressure," Advances in Civil Engineering, vol. 2018, Article ID 4068918, 10 pages, 2018.

[8] M. Wang and W. Wan, "A new empirical formula for evaluating uniaxial compressive strength using the Schmidt hammer test," International Journal of Rock Mechanics and Mining Sciences, vol. 123, Article ID 104094, 2019.

[9] J. Hu, G. Wen, Q. Lin, P. Cao, and S. Li, "Mechanical properties and crack evolution of double-layer composite rock-like specimens with two parallel fissures under uniaxial compression," Theoretical and Applied Fracture Mechanics, vol. 108, Article ID 102610, 2020.

[10] R.-h. Cao, C. Wang, R. Yao et al., "Effects of cyclic freeze-thaw treatments on the fracture characteristics of sandstone under different fracture modes: laboratory testing," Theoretical and Applied Fracture Mechanics, 2020, In press, Article ID 102738.

[11] Y. Wang, H. Zhang, H. Lin, Y. Zhao, X. Li, and Y. Liu, "Mechanical behavior and failure analysis of fracture-filled gneissic granite," Theoretical and Applied Fracture Mechanics, vol. 108, Article ID 102674, 2020.

[12] Q. Lin, P. Cao, R. Cao, and X. Fan, "Acoustic emission characteristics during rock fragmentation processes induced by disc cutter under different water content conditions," Applied Sciences, vol. 9, no. 1, p. 194, 2019.

[13] R. H. C. Wong, C. M. Law, K. T. Chau et al., "Crack propagation from 3-D surface fractures in PMMA and marble specimens under uniaxial compression," International Journal of Rock Mechanics and Mining Sciences, vol. 41, no. 37, 2004.

[14] L. N. Y. Wong and H. H. Einstein, "Systematic evaluation of cracking behavior in specimens containing single flaws under uniaxial compression," International Journal of Rock Mechanics and Mining Sciences, vol. 46, no. 2, pp. 239-249, 2009.

[15] P. Yin, R. H. C. Wong, and K. T. Chau, "Coalescence of two parallel pre-existing surface cracks in granite," International Journal of Rock Mechanics and Mining Sciences, vol. 68, pp. 66-84, 2014. 
[16] J. Lee, J.-W. Hong, and J.-W. Jung, "The mechanism of fracture coalescence in pre-cracked rock-type material with three flaws," Engineering Geology, vol. 223, pp. 31-47, 2017.

[17] Q. Lin, P. Cao, and R. Cao, "Experimental investigation of jointed rock breaking under a disc cutter with different confining stresses," Comptes Rendus Mécanique, vol. 346, no. 9, pp. 833-843, 2018.

[18] C. Zhang, H. Lin, C. Qiu et al., "The effect of cross-section shape on deformation, damage and failure of rock-like materials under uniaxial compression from both a macro and micro viewpoint," International Journal of Damage Mechanics, vol. 29, no. 7, pp. 1076-1099, 2020.

[19] X. Fan, H. Lin, H. Lai, R. Cao, and J. Liu, "Numerical analysis of the compressive and shear failure behavior of rock containing multi-intermittent joints," Comptes Rendus Mécanique, vol. 347, no. 1, pp. 33-48, 2019.

[20] R. Cao, R. Yao, J. Meng, Q. Lin, H. Lin, and S. Li, "Failure mechanism of non-persistent jointed rock-like specimens under uniaxial loading: Laboratory testing," International Journal of Rock Mechanics and Mining Sciences, vol. 132, Article ID 104341, 2020.

[21] Q.-b. Lin, P. Cao, K.-h. Li, R.-h. Cao, K.-p. Zhou, and H.-w. Deng, "Experimental study on acoustic emission characteristics of jointed rock mass by double disc cutter," Journal of Central South University, vol. 25, no. 2, pp. 357-367, 2018.

[22] M. Wang, W. Wan, and Y. Zhao, "Experimental study on crack propagation and the coalescence of rock-like materials with two preexisting fissures under biaxial compression," Bulletin of Engineering Geology and the Environment, vol. 79, no. 6, pp. 3121-3144, 2020.

[23] R.-h. Cao, P. Cao, H. Lin, C.-z. Pu, and K. Ou, "Mechanical behavior of brittle rock-like specimens with pre-existing fissures under uniaxial loading: experimental studies and particle mechanics approach," Rock Mechanics and Rock Engineering, vol. 49, no. 3, pp. 763-783, 2016.

[24] H. Lin, H. Yang, Y. Wang, Y. Zhao, and R. Cao, "Determination of the stress field and crack initiation angle of an open flaw tip under uniaxial compression," Theoretical and Applied Fracture Mechanics, vol. 104, Article ID 102358, 2019.

[25] R. H. Cao, P. Cao, H. Lin, G. W. Ma, C. Y. Zhang, and C. Jiang, "Failure characteristics of jointed rock-like material containing multi-joints under a compressive-shear test: experimental and numerical analyses," Archives of Civil and Mechanical Engineering, vol. 18, no. 3, pp. 784-798, 2018.

[26] Y. Wang, H. Zhang, H. Lin, Y. Zhao, and Y. Liu, "Fracture behaviour of central-flawed rock plate under uniaxial compression," Theoretical and Applied Fracture Mechanics, vol. 106, Article ID 102503, 2020.

[27] Q. Yin, H. Jing, and H. Su, "Investigation on mechanical behavior and crack coalescence of sandstone specimens containing fissure-hole combined flaws under uniaxial compression," Geosciences Journal, vol. 22, no. 5, pp. 825-842, 2018.

[28] H. Chen, X. Fan, H. Lai, Y. Xie, and Z. He, "Experimental and numerical study of granite blocks containing two side flaws and a tunnel-shaped opening," Theoretical and Applied Fracture Mechanics, vol. 104, Article ID 102394, 2019.

[29] D. Li, Q. Zhu, Z. Zhou, X. Li, and P. G. Ranjith, "Fracture analysis of marble specimens with a hole under uniaxial compression by digital image correlation," Engineering Fracture Mechanics, vol. 183, pp. 109-124, 2017.

[30] H. Wu, G. Zhao, and W. Liang, "Mechanical properties and fracture characteristics of pre-holed rocks subjected to uniaxial loading: a comparative analysis of five hole shapes," Theoretical and Applied Fracture Mechanics, vol. 105, Article ID 102433, 2020.

[31] Y. L. Gui, J. L. Shang, J. J. Ma, and Z. Y. Zhao, "Numerical study of the circular opening effect on mechanical behaviour of rock under confinement," Journal of Rock Mechanics and Geotechnical Engineering, vol. 11, no. 6, pp. 1201-1210, 2019.

[32] X. Fan, K. Li, H. Lai, Y. Xie, R. Cao, and J. Zheng, "Internal stress distribution and cracking around flaws and openings of rock block under uniaxial compression: a particle mechanics approach," Computers and Geotechnics, vol. 102, pp. 28-38, 2018.

[33] R. H. Cao, P. Cao, H. Lin, G. W. Ma, X. Fan, and X. G. Xiong, "Mechanical behavior of an opening in a jointed rock-like specimen under uniaxial loading: experimental studies and particle mechanics approach," Archives of Civil and Mechanical Engineering, vol. 18, no. 1, pp. 198-214, 2018.

[34] Q. Lin, P. Cao, R. Cao et al., "Mechanical behavior around double circular openings in a jointed rock mass under uniaxial compression," Archives of Civil and Mechanical Engineering, vol. 20, no. 1, p. 19, 2020.

[35] Q. Lin, P. Cao, J. Meng, R. Cao, and Z. Zhao, "Strength and failure characteristics of jointed rock mass with double circular holes under uniaxial compression: insights from discrete element method modelling," Theoretical and Applied Fracture Mechanics, vol. 109, Article ID 102692, 2020.

[36] ISRM, "Suggested methods for determining the uniaxial compressive strength and deformability of rock materials," International Journal of Rock Mechanics and Mining Sciences, vol. 16, no. 2, pp. 138-140, 1979.

[37] P. Cao, L. He, and G. Tang, "Experimental study on failure characteristics of jointed rock mass under staged unloading conditions," Journal of Vibroengineering, vol. 21, no. 4, pp. 927-939, 2019.

[38] C. H. Park and A. Bobet, "Crack coalescence in specimens with open and closed flaws: a comparison," International Journal of Rock Mechanics and Mining Sciences, vol. 46, no. 5, pp. 819-829, 2009.

[39] P. Cao, T. Liu, C. Pu, and H. Lin, "Crack propagation and coalescence of brittle rock-like specimens with pre-existing cracks in compression," Engineering Geology, vol. 187, pp. 113-121, 2015. 